\title{
Filosofia da diferença: interfaces educacionais
}

\section{José Rogério Vitkowski}

\section{Resumo}

Esse artigo tem como objeto de estudo o conceito de filosofia e seus desdobramentos na filosofia da educação, no âmbito da formação docente. O eixo teórico-metodológico se ancora na filosofia da diferença ou da multiplicidade, na perspectiva dos filósofos franceses Gilles Deleuze e Felix Guattari. Os autores apregoam como função principal da filosofia a criação de conceitos. Nessa perspectiva a filosofia da educação encontra uma trilha metodológica singular que se dá através de processos de desterritorialização de conceitos para o plano de imanência educacional.

Palavras-chave: Filosofia da educação; Filosofia da diferença; Formação docente.

\section{Résumé}

Cet article a comme l'objet de la recherce le concept de philosophie et ses développements dans la philosophie de l'éducation au cadre de la formation des enseignants. L'axe théorique et méthodologique est ancré dans la philosophie de la différence ou de la multiplicité, des philosophes français Gilles Deleuze et Felix Guattari. Les auteurs annoncent, comme la fonction principale de la philosophie, la création des concepts. Dans cette perspective et grâce aux processus de déterritorialisation des concepts pour le plan de l'immanence éducatif, la philosophie de l'éducation trouve une chemin méthodologique singulier.

Mots-clés: Philosophie de l'éducation; Philosophie de la différence ; Formation des enseignants.

${ }^{1}$ Doutor em Educação, professor de Filosofia e Fundamentos da Educação, lotado no Departamento de Educação, Universidade Estadual de Ponta Grossa (UEPG), PR. 
$\mathrm{D}$ a paideia grega até nossos dias, a filosofia se faz presente nos espaço-tempos educacionais. Essa presença se materializa a partir de variedade de propostas e de modelos recorrentes e, portanto, passíveis de critica e de revisão. Com frequência a filosofia tem sido inserida, por exemplo, em modelos de ensino meramente enciclopédico e conteúdístico, outras vezes, assume um rosto historicista panfletário, ou ainda, se apresenta como uma "reflexão sobre os problemas educacionais". Não negamos a importância da historia da filosofia, ou de conteúdos histórico-sociais como integrantes de grades curriculares. No entanto, nos preocupamos com o dúbio estatuto que frequentemente se estabelece para a filosofia da e na educação. Nesse sentido, afirmamos que a questão da presença da filosofia na formação docente e seus possíveis contributos se apresentam muito mais como um problema filosófico do que meramente pedagógico, embora não o exclua.

Esse problema não é recente e já foi abordado por filósofos de diferentes épocas e tradições. Referindo-se aos jovens e ao ensino da filosofia, Nietzsche (1983, p.81) ironicamente questionava:

[...] em que neste mundo importa aos nossos jovens a história da filosofia? Será que eles devem, pela confusão das opiniões ser desencorajados de terem opiniões? Será que devem ser ensinados a participar do coro de júbilo: como chegamos tão esplendidamente longe? Será que, porventura, devem aprender a odiar ou desprezar a filosofia?

O polêmico pensador da Basiléia é incisivo com relação aos resultados de práticas escolares que não levam o aluno a estabelecer uma relação de amizade com o conhecimento filosófico. Aprender a odiar ou a desprezar a filosofia é um resultado indesejado, todavia, frequente. Daí emerge a indagação: como mudar esse quadro?

Karl Jaspers (1971, p.137) acrescenta um ingrediente explosivo nessa mistura ao afirmar e interrogar: "Por força da tradição, a filosofia é 
polidamente respeitada, mas, no fundo, objeto de desprezo. A opinião corrente é a de que a filosofia nada tem a dizer e carece de qualquer utilidade prática."

Este texto, lapidar e desconcertante; nos desperta um sentimento de indignação, pois é frequente encontrar em propostas educativas concepções neotecnicistas eivadas de um utilitarismo debochado - e até hostil - no qual se proclama a filosofia como "inútil”. Perguntamos: inútil para quem, inútil por quê?

Esses cenários e constatações, ainda que amplas, ilustram os limites e reducionismos da presença da filosofia nos espaços-tempos educacionais que por certo têm afetado as práticas formativas, empobrecendo-as. Por isso mesmo, entendemos a necessidade constante de revisão do estatuto da filosofia cujo tema acaba por remeter à antiga mas sempre atual pergunta: o que é filosofia?

Aqui partilhamos que em nossa trajetória como educador nos defrontamos intensamente com os descompassos que envolvem o ensino e a aprendizagem da filosofia. Um embate denso e tenso, quase agônico, se instalou e exigiu que tomássemos a decisão de estabelecer um diálogo franco conosco próprios e com a tradição filosófica na busca de alguma resposta, pois no final de contas colocávamos em questão qual a concepção de filosofia que estava subjacente em nossa prática profissional.

Foi então que, qual fênix que renasce, ocorreu um encontro com os filósofos Deleuze e Guattari e com a pergunta que ainda não sabíamos formular devidamente, mas que culminava com a mesma indagação dos filósofos: o que é isso que fiz toda a minha vida?

Nessa perspectiva de enfrentamento do problema buscamos neste texto revisitar uma concepção de filosofia que nos parece interessante; aquela proposta pelos filósofos franceses Gilles Deleuze e Félix Guattari. Num texto (1992) já considerado clássico os filósofos perguntam afinal “o que é a filosofia?". Nas primeiras palavras daquela obra os autores expressam uma espécie de confissão: 
Talvez só possamos colocar a questão $O$ que é a filosofia? tardiamente, quando chega a velhice, e a hora de falar concretamente. [...] É uma questão que enfrentamos numa agitação discreta, à meia-noite, quando nada mais resta a perguntar. (DELEUZE \& GUATTARI, 1992, p. 9)

Há nessa interrogação deleuziana ${ }^{2}$ uma intensidade dramática com tons de poesia. Essa interrogação indicava doravante um caminho a ser percorrido e que nos forneceria os seguintes balizamentos nocionais. A resposta apresentada por Deleuze e Guattari $(1992$, p.10) para "o que é filosofia” não era outra senão: "a filosofia é a arte de formar, de inventar, de fabricar conceitos". Essa pergunta-resposta devia ser formulada agora "entre amigos", como uma confidência ou uma confiança, ou então "face ao inimigo como a um desafio". Os autores trazem à cena uma bela indicação do filósofo, cuja atividade é doravante, designada com singularidade:

o filósofo é o amigo do conceito, ele é conceito em potência [...] pois os conceitos não são necessariamente formas, achados ou produtos. [...] Os conceitos não nos esperam inteiramente feitos, como corpos celestes. Não há céu para os conceitos. Eles devem ser inventados, fabricados ou antes criados, e não seriam nada sem a assinatura daqueles que os criam. (DELEUZE \& GUATTARI, p. 13)

Assim a filosofia mostra-se como produção, como ato especialmente criativo, e o filósofo torna-se uma espécie de artesão que produz seus conceitos e neles imprime as marcas de seu esforço de pensar, por isso mesmo levam a assinatura do seu criador.

Essa criação, é por sua vez, assinada, e exige uma atenção à linguagem: mônada de Leibnitz, cogito de Descartes, duração de Bergson e tantos outros. Se existem palavras extraordinárias, bárbaras ou chocantes, também há o uso de palavras correntes, comuns. Alguns conceitos solicitam arcaísmos, neologismos, exercícios etimológicos quase loucos. De acordo com Deleuze

${ }^{2}$ Doravante utilizaremos a expressão deleuziana $(o)$ para referirmo-nos à obra conjunta dos filósofos Gilles Deleuze e Félix Guattari. 
e Guattari (1992, p. 16), isso tudo são elementos de um estilo: há um batismo do conceito que

solicita um gosto propriamente filosófico que procede com violência ou com insinuação, e que constitui na língua uma língua da filosofia, não somente um vocabulário, mas uma sintaxe que atinge o sublime ou uma grande beleza.

Se a filosofia é criação e o filósofo um criador, é importante destacar alguns equívocos que envolvem algumas concepções de filosofia. A filosofia não pode ser concebida, na sua especificidade, nem como contemplação, nem comunicação, nem reflexão, "mesmo se ela pôde acreditar ser ora uma, ora outra coisa, em razão da capacidade que toda disciplina tem de engendrar suas próprias ilusões" (DELEUZE \& GUATTARI, 1992, p. 14).

A filosofia não é contemplação, pois essa noção de matriz platônica visa as coisas mesmas, enquanto preexistentes. Também não é comunicação, que busca criar consensos, e não o conceito, que pode gerar dissensos. E a filosofia também não é reflexão, pois no limite, qualquer cidadão pode refletir sobre qualquer coisa. Os autores são explícitos:

Ela não é reflexão, porque ninguém precisa de filosofia para refletir sobre o que quer que seja: acredita-se dar muito à filosofia fazendo dela a arte da reflexão, mas retira-se tudo dela, pois os matemáticos como tais não esperaram jamais os filósofos para refletir sobre a matemática, nem os artistas sobre a pintura ou a música; dizer que eles se tornam então filósofos é uma brincadeira de mau gosto, já que sua reflexão pertence à sua criação respectiva (DELEUZE \& GUATTARI, 1992, p. 14)

Note-se que o texto faz uma dura crítica ao reducionismo da concepção de filosofia "como reflexão", todavia, é bom que se assinale, não se trata de execrar a noção de reflexividade, enquanto componente e como instrumento do pensamento. Aliás, a singularidade da atividade filosófica padece de outras determinações, algumas delas até interessantes como: conhecer-se a si 
mesmo, fazer como se nada fosse evidente, espantar-se. Para os autores franceses, apesar de interessantes, elas não constituem uma noção bem definida, uma atividade precisa. Assim Deleuze \& Guattari propõem a noção de filosofia como criação de conceitos.

Entretanto, se filosofia remete à criação conceitual, inevitavelmente surge a pergunta: afinal, o que é um conceito? Ora, o conceito foi sempre tomado como um dado já posto ou estabelecido, algo que não precisa ser explicado. Assim, é importante rever a "conceituação do conceito".

Gallo (2008) alerta para essa dificuldade e sugere um aprendizado que passa pela desconstrução das noções prévias sobre o tema. Comumente tomase o conceito por noção, definição, representação mental. Para o filósofo brasileiro, a definição deleuziana de conceito é concomitantemente mais e menos do que estamos acostumados a lidar. Assim, o conceito não é apenas um operador lógico; é mais do que isso e menos que isso, na medida em que se coloca para além da lógica e para aquém da lógica. E tampouco o conceito é um universal, pois é próprio do conceito expressar ou colocar o acontecimento, que é singular.

Desse modo, é bom frisar, o conceito na perspectiva deleuziana não é uma representação, muito menos uma representação universal. Pode-se defini-lo, como "uma aventura do pensamento que institui um acontecimento, vários acontecimentos, que permita um ponto de visada sobre o mundo, sobre o vivido" (DELEUZE \& GUATTARI, 2008, p. 39). Daí, a possibilidade permanente de reaprender o vivido e de ressignificar o mundo, os acontecimentos. Nada mais sugestivo para a educação e para os educadores, sejam eles filósofos ou não. Bem o sabemos, diuturnamente devemos enfrentar os desafios da doxa, do senso comum que se traveste de roupagens insuspeitas.

Nesse enfrentamento se faz necessário desenvolver uma pedagogia do conceito $^{3}$, aqui compreendida de acordo com Bianco (2005, p. 1230) como

\footnotetext{
${ }^{3}$ Conforme BIANCO (2005), é essencial compreender que por "pedagogia do conceito" não devemos entender uma prática pedagógica que utiliza o conceito como o seu instrumento privilegiado, mas um tipo particular de conceito que é pedagógico por natureza. Em suma, não é tanto o conceito que é $d a$ pedagogia, mas é, sobretudo, a pedagogia, a "pedagogicidade", que é do conceito.
} 
uma postura do pensamento que "pode permitir à filosofia fugir do niilismo da doxa do discurso pseudofilosófico da disciplina da comunicação, contra o qual Deleuze lutou durante toda sua trajetória".

Essa pedagogia do conceito é composta por uma série de características descritas por Deleuze e que assinalamos sucintamente.

A primeira, já mencionada neste texto, é a de que todo conceito é assinado pelo filósofo. Como vimos, essa assinatura remete ao estilo filosófico de cada autor e se desenvolve gradativamente ao longo da trajetória de cada pensador.

Não há conceito simples. Assim, todo conceito é uma multiplicidade. Tem componentes e se define por eles, quando os totaliza. Caleidoscopicamente, gera a cada movimento novas possibilidades.

Todo conceito remete a um problema, a problemas sem os quais não teria sentido. Problemas novos, ou mal colocados; é a partir dos problemas que o filósofo cria conceitos.

Todo conceito tem uma história. Essa história é marcada pelo ziguezague, ou seja, pelo ir e vir, pelos cruzamentos. Num conceito, há, no mais das vezes, pedaços ou componentes vindos de outros conceitos, que respondiam a outros problemas e supunham outros planos.

Todo conceito remete a e se relaciona com outros conceitos. Em conformidade com Deleuze \& Guattari (1992, p. 30), um conceito "não exige somente um problema sob o qual remaneja ou substitui conceitos precedentes, mas uma encruzilhada de problemas em que se alia a outros conceitos coexistentes". Desse modo,

cada conceito remete a outros conceitos, não somente em sua história, mas em seu devir ou suas conexões presentes. Cada conceito tem componentes que podem ser, por sua vez, tomados como conceitos [...]. Os conceitos vão pois ao infinito e, sendo criados, não são jamais criados do nada. (DELEUZE \& GUATTARI, 1992, p. 31)

Todo conceito é uma ordenação de seus componentes por zonas de vizinhanças, ou seja, é uma heterogênese. Assim cada conceito é um ponto de 
coincidência, de condensação ou de acumulação de seus próprios componentes. Desta forma, de acordo com Gallo (2008, p. 41) uma filosofia: "não deve jamais ser vista como sistema, como resposta absoluta a todos as perguntas, mas como respostas possíveis e problemas possíveis num determinado mundo vivido".

Embora se encarne ou se efetue nos corpos, todo conceito é um incorporal. Mas não se confunde com o estado de coisas no qual se efetua. Não tem coordenadas espaço-temporais, mas ordenadas intensivas. Assim, o conceito diz o acontecimento, não a essência ou a coisa.

O conceito é ainda, absoluto e relativo. Relativo a seus próprios componentes, aos outros conceitos, aos problemas que se supõe deva resolver. Todavia, é absoluto pela condensação que opera na busca de resposta a um problema. Para Deleuze e Guattari (1992, p. 34) o conceito:

É infinito por seu sobrevoo ou sua velocidade, mas finito por seu movimento que traça o contorno de seus componentes. Um filósofo não pára de remanejar seus conceitos, e mesmo de mudá-los; basta às vezes um ponto de detalhe que se avoluma, e produz uma nova condensação, acrescenta ou retira componentes [...]. A relatividade e a absolutidade do conceito são como a sua pedagogia e sua ontologia, sua criação e sua autoposição, sua idealidade e sua realidade.

Por fim, o conceito não é discursivo, não é proposicional. Essa é uma função da ciência. Distinguindo a arte, a ciência e a filosofia, os autores esclarecem a função de cada modo de conhecimento:

das frases ou de um equivalente, a filosofia tira conceitos (que não devem ser confundidos com ideias gerais ou abstratas), enquanto que a ciência tira prospectos (proposições que não se confundem com juízos) e a arte tira perceptos e afetos (que também não se confundem com percepções e sentimentos). Em cada caso, a linguagem é submetida a provas e usos incomparáveis, mas que não definem a diferença entre as disciplinas sem constituir também seus cruzamentos perpétuos. (Deleuze e Guattari (1992, p. 37) 
Percebe-se assim a indicação de que somente a filosofia produz conceitos, embora transversalize e tangencie outros campos do saber. O conceito é então um dispositivo, um agenciamento, um operador, algo que faz acontecer. Acompanhando as observações de Gallo (2008, p. 43), inferimos que o conceito não é uma entidade metafisica, ou um mero operador lógico, ou ainda, uma representação mental.

O conceito é um dispositivo, uma ferramenta, algo que é inventado, criado, produzido, a partir das condições dadas e que opera no âmbito mesmo destas condições. O conceito é um dispositivo que faz pensar, que permite, de novo pensar. $\mathrm{O}$ que quer dizer que o conceito não indica, não aponta uma suposta verdade, o que paralisaria o pensamento; ao contrário, o conceito é justamente aquilo que nos põe a pensar. Se o conceito é produto, ele é também produtor: produtor de novos pensamentos, produtor de novos conceitos; e, sobretudo, produtor de acontecimentos, na medida em que é o conceito que recorta o acontecimento, que o torna possível.

Desse modo, há um estatuto pedagógico do conceito, por meio da articulação dos vários elementos do mecanismo de conceituação. Esse movimento de criação conceitual se dá no solo ou horizonte, denominado de plano de imanência, o qual pode ser compreendido como um campo onde se produzem, circulam e se entrechocam os conceitos. Nesse plano, atuarão o(s) sujeito(s) de produção conceitual, como elemento(s) criador(es).

A filosofia é, então, constituída pelas três instâncias: o plano de imanência que precisa traçar, os personagens filosóficos que precisa inventar e os conceitos que deve criar. Essa é a trindade filosófica! Ela permite que a filosofia enfrente a doxa, isto é, a opinião que tudo quer abarcar. A opinião luta contra a multiplicidade de possibilidades que estão presentes, naquilo que os autores denominaram "caos".

Há três possibilidades de saberes que mergulham e recortam o caos, produzindo significações: a arte, que cria afetos, sensações; a ciência, criadora de prospectos (conhecimentos), e a filosofia que produz conceitos. 
Elas não se reduzem uma à outra, mas há uma interação entre elas. Nem tampouco há hierarquia ou proeminência de uma sobre outra. Cada uma é uma reação contra a opinião que promete o impossível: vencer o caos. Assim sendo, as figuras do filósofo, do cientista e do artista, cada uma, a seu modo, contribuem para que a multiplicidade seja viável. A filosofia é, portanto, esforço de luta contra opinião que se generaliza e escraviza e, ao mesmo tempo, criação de conceitos que faz emergir acontecimentos.

Nesse projeto incessante de tirar o pensamento da imobilidade brilha também no pensamento deleuziano a noção de "intercessores". Os intercessores, no plural, são quaisquer encontros que fazem com que o pensamento se movimente. De acordo com Deleuze (1992b, p. 156):

O essencial são os intercessores. A criação são os intercessores. Podem ser pessoas - para um filósofo, artistas ou cientistas; para um cientista, filósofos ou artistas - mas também coisas, plantas, até animais, como em Castañeda. Fictícios ou reais, animados ou inanimados, é preciso fabricar seus próprios intercessores.

Nesse texto se reivindica que literatos, escritores, poetas, músicas, cientistas, e até mesmo objetos encontrem um espaço importante no movimento do pensamento especificamente filosófico, que é o de criar conceitos. Com os intercessores a filosofia da multiplicidade transborda no seu movimento de investigação e de relação com o extrafilosófico. Através dos intercessores, se dá a criação.

Essa experiência de pensamento é um convite estendido aos educadores e educandos, mesmo sem serem especialistas, pois todos podem, em seu nível, em contato com a filosofia, desenvolver essas experiências de pensamento, de construção de conceitos. Essa possibilidade evidentemente, não prescinde da história da filosofia, mas não se limita a ela. O diálogo com a história é uma forma de pensar o novo, repensando o já pensado, ou desterritorializando o já pensado. Mas essa repetição é criativa e é também um roubo. 
A produção filosófica necessita de encontros, de achados, de capturas de roubos "mas não há método para achar, nada além de uma longa preparação. Roubar é o contrário de plagiar, de copiar, de imitar ou de fazer como". (DELEUZE e PARNET, 1988, p. 6).

Na obra Diálogos Deleuze cita um poema de Bob Dylan que se refere ao "roubo":

Sim, sou um ladrão de pensamento não, por favor,

Um ladrão de almas

Eu construí e reconstruí

Sobre o que está à espera

Pois a areia nas praias

Esculpe muitos castelos

No que foi aberto

Antes de meu tempo

Uma palavra, uma ária, uma história, uma linha

Chaves no vento para que minha mente fuja

E fornecer a meus pensamentos fechados uma corrente de ar fresco. (DELEUZE e PARNET, 1988, p.7).

Com roubos intensos, a produção conceitual ganha fecundidade, estabelece encontros e conexões inusitadas, respira ar fresco. Desse modo, toda leitura é vista com um caráter instrumental pelo qual se pode realizar roubos, colagens, como caminho para a criação de conceitos. Além do mais, nesse procedimento de leitura, Deleuze também afirma que não se deve procurar se uma ideia é justa ou verdadeira: "Seria preciso procurar uma ideia bem diferente, em outra parte, em outro domínio, tal que entre os dois alguma coisa se passe, que não está nem em um nem em outro". (DELEUZE e PARNET, 1988, p. 9).

Acrescenta ainda que não há nenhuma questão de interpretação, pois os conceitos "são exatamente como sons, cores ou imagens, são intensidades que convêm a você ou não, que passam ou não passam. Não há nada a compreender, nada a interpretar". (DELEUZE e PARNET, 1988, p.11). 
Desse modo, não há nada em cima - céus da transcendência - nem embaixo - brumas da essência.

A partir dessas noções é possível abordar múltiplas interfaces da filosofia da diferença com os processos de formação em diversos espaçotempos educativos.

\section{Considerações finais}

À guisa de finalização diante da diversidade de interfaces que emergem a partir desse texto, referenciamos a proposta de vanguarda, já desenvolvida por Gallo (2008). Ao se perguntar o que é possível dizer sobre educação a partir de Deleuze, o filósofo brasileiro responde com a indicação de um procedimento: o de realizar deslocamentos conceituais da filosofia deleuziana para a educação. Desse modo, em sintonia com o autor faremos um breve aceno para alguns desses deslocamentos aos quais aduziremos nossa contribuição. Nosso esforço de escrita se dá por meio da fórmula escrever a n, n-1. No contexto da presença da filosofia nos espaços de formação nos parece importante reafirmar a proposta de se entender a filosofia da educação enquanto criação conceitual.

Nunca é demais frisar que nessa perspectiva, a filosofia se apresenta como uma atividade que deve nos fazer pensar. E pensar, para Deleuze, não se reduz à ordem da teoria, do abstrato, da boa conduta do raciocínio, que opera por exclusão, pela obsessão do falso versus verdadeiro. Esse procedimento nos leva frequentemente a pactuar com a imagem dogmática do pensamento, fruto de uma filosofia racionalista, com fins pretensiosos de universalidade. Aliás, essa imagem dogmática do pensamento, que nos leva à recognição - bom dia, Teeteto - apresenta-se certamente como uma grande ruptura a ser efetuada pela atividade filosófica. Pensar, para Deleuze, se vincula ao jogo de forças que nos tiram da zona de conforto da recognição e, portanto, abrem-se as portas à experimentação, aos acontecimentos, enfim, às intensidades que brotam dos encontros com os intercessores. Hoje compreendemos que não se trata de apresentarmos, em nome da filosofia, 
verdades deleuzianas para a educação, mas, antes, na perspectiva da criação de conceitos, realizarmos exercícios de pensamento que nos façam pensar.

Se pretendemos escapar dos limites das concepções da filosofia com tonalidades eminentemente reflexivas, ou conteudísticas, cabe-nos enquanto filósofos-educadores o desafio da criação de conceitos no plano de imanência da educação. Aceitar essa proposta nos coloca em contato com refinada tradição que entende a formação humana e seus processos como processos de autoformação. Retomamos aqui o célebre grito de Nietzsche "chega a ser o que tu és”. E se aguçarmos nossa visão e ouvidos perceberão - chega a ser o que és aprendendo a sê-lo. ${ }^{4}$ Tornar-se o que se é sugere, portanto, um movimento contínuo que se volta para fazer emergir as singularidades que produzem a vida docente, para além dos ditames da educação maior e dos processos de subjetivação vigentes ${ }^{5}$.

Nessa perspectiva incumbe ao filósofo educador operar rasgos no mundo das opiniões tão presentes na educação. A educação enquanto campo aberto tem sido loteada e povoada por todo tipo de interesse no qual a doxa efetivamente se exibe adotando trajes de realeza, tal como o rei vaidoso do conto de Christian Andersen. Diante da ambição do rei e da esperteza dos embusteiros - vendedores de roupas invisíveis - a história nos narra uma situação insólita na qual o rei acaba desfilando pelado numa manifestação

4 "Homem, torna-te no que és", lema de Píndaro, poeta grego (522-443 a.C), muito caro a Nietzsche, o qual, inclusive, assume como subtítulo de Ecce Homo - como alguém se torna o que é (1995), sua autobiografia intelectual.

${ }^{5}$ Gallo (2010) considera que, diante da complexidade do processo educativo, há, de um lado, aqueles que educam para que o ser humano possa chegar a ser aquilo que é; de outro lado, aqueles que educam para que o ser humano venha a ser aquilo que não é. Com isso pode-se compreender a educação como um processo de formar as pessoas segundo as potencialidades que elas vão revelando durante o próprio processo (que pode ser chamado de singularização) ou como um processo de formar os indivíduos de acordo com os padrões definidos socialmente de antemão (o que pode ser designado de subjetivação). Os indivíduos subjetivados ganham uma identidade e um papel, através do processo educativo, para desempenhar um conjunto de funções que deles se espera. É o que se pode chamar de processo de serialização na educação, uma produção em massa de indivíduos para atender às necessidades da máquina social. Neste contexto, não há muito espaço para a criação e para a invenção de si mesmo. Essa questão da produção maquínica de subjetividades foi largamente tratada como a dimensão ideológica da educação. (GALLO, 2010 p. 230s) 
popular até que uma criança desmascara a situação com um grito: o rei está nu! Ao que todos os súditos ecoam: sim, o rei está nu. ${ }^{6}$

Sim, o devir-criança manifesta que, na educação, o rei está nu quando os discursos politicamente corretos da educação maior impingem fardos inexequíveis ao trabalho do professor; o rei está nu quando o séquito dos gestores se submete ao faz-de-conta nas instituições; o rei está nu quando colegas de trabalho viram patrões; nu quando professores se digladiam nas relações de micropoder; o rei está nu quando o produtivismo neotecnicista invade as práticas de pesquisa tornando-as estéreis; está nu quando os discursos filisteus intentam silenciar vozes dissonantes e alternativas. $\mathrm{O}$ rei está nu quando continuamos a procurar a identidade única da pedagogia; o rei está nu quando teimamos em reproduzir na formação de professores as concepções e práticas de uma ciência arbórea que tudo fragmenta, tudo divide, tudo controla. ${ }^{7}$

Certamente o rompimento com o universo da doxa demanda o desenvolvimento de uma nova epistemologia que se contraponha à lógica arbórea e que seja pautada no conceito de rizoma. Talvez assim encaminhemos a construção de subjetividades renovadas, pautadas numa única repetição: aquela que repete a diferença.

Encerramos este artigo apresentando um trecho memorável de Mil Platôs, no qual Deleuze (2011, p.48) nos deixa uma pérola:

Nunca suscite um General em você!

Nunca ideias justas, justo uma ideia.

Tenha ideias curtas.

Faça mapas, nunca fotos nem desenhos.

\footnotetext{
${ }^{6}$ Hans Christian Andersen (1805-1875), escritor dinamarquês, gostava de contar histórias, dentre elas a do Rei que se deixou enganar ao adquirir roupas fictícias que tinham a especialidade de parecer invisíveis às pessoas destituídas de inteligência ou àquelas que não estavam aptas para os cargos que ocupavam. O Rei deixou-se levar pelos tecelões embusteiros e por sua corte, que se omitiu, e acabou por desfilar nu, no meio do povo de seu reino, até que uma criança gritou e desmascarou a farsa gritando: o rei está nu.

${ }^{7}$ Sabemos que o paradigma arborescente de ciência porta uma concepção mecânica do conhecimento e da realidade, reproduzindo a fragmentação cartesiana-newtoniana do saber, resultado das concepções científicas modernas estruturadas em hierarquias de conhecimento e com fronteiras e regiões de domínio praticamente intransponíveis.
} 
Seja a Pantera Cor-de-Rosa e que vossos amores sejam como a vespa e a orquídea.

Provavelmente esse texto foi escrito com leveza e bom humor, características que nos parecem extremamente necessárias no desenvolvimento de processos autoformativos.

\section{Referências}

BIANCO, Giuseppe. Otimismo, pessimismo, criação: pedagogia do conceito e resistência. Educação e Sociedade. Campinas, v. 26, n. 93, p. 1289-1308, Set/Dez 2005.

DELEUZE, Gilles. Conversações. 1.ed. Trad. Peter Pál Pelbart. Rio de Janeiro: Ed. 34, 1992b.

Proust e os Signos. 2.ed. Rio de Janeiro: Forense Universitária, 2003.

Diferença e repetição. 2.ed. Trad. Luiz Orlandi e Roberto Machado. Rio de Janeiro: Graal, 2006.

DELEUZE, Gilles; GUATTARI, Félix. O que é a filosofia? 2.ed. Trad. Bento Prado Jr. e Alberto Alonso Muñoz. Rio de Janeiro: Ed. 34, 1992.

DELEUZE, Gilles; GUATTARI, Félix. Mil Platôs. V.2. 1.ed. São Paulo: Ed. 34, 1995.

DELEUZE, Gilles; PARNET, Claire. Diálogos. Trad. Eloísa Araújo Ribeiro. São Paulo: Escuta, 1988.

GALLO, Silvio. Deleuze e a Educação. 2.ed. Belo Horizonte. Autêntica, 2008. . Educação: entre a subjetivação e a singularidade. Revista do Centro de Educação. Santa Maria, v. 35, n. 2, p. 229-243, 2010.

JASPERS, Karl. Introdução ao pensamento filosófico. Trad. Leonidas Hegenberg e Octanny Silveira da Mota. São Paulo, Cultrix, 1971.

NIETZSCHE, Friedrich. Ecce homo: como alguém se torna o que é. Trad. Paulo Cesar de Souza. São Paulo: Companhia das Letras, 1995.

- Considerações Extemporâneas III - Schopenhauer como educador. In: Obras Incompletas. 3.ed. Seleção de textos Gérard Lebrun. Trad. Rubens

Rodrigues Torres Filho. São Paulo: Abril Cultural, 1983, p. 53-81. (Col. Os Pensadores.) 